\title{
The impact of nest tube dimensions on reproduction parameters in a cavity nesting solitary bee, Osmia bicornis (Hymenoptera: Megachilidae)
}

\author{
Karsten Seidelmann, Adrienne Bienasch, Franziska PröHL \\ Martin-Luther-Universität Halle-Wittenberg, Institut für Biologie/Zoologie, Abteilung Tierphysiologie, Domplatz 4, \\ 06099, Halle, Saale, Germany
}

Received 12 February 2015 - Accepted 30 June 2015

\begin{abstract}
Recent declines of bee populations have led to great interest in preserving bee species and fuel efforts to develop solitary species for pollination purposes. Xylophilous solitary bees can be easily reared in artificial nests tubes for commercial agricultural as well as wild plant pollination. The impact of the dimensions of these artificial nest tubes on reproduction parameters was studied in the red mason bee, Osmia bicornis (L.), in a long-term study. Increasing tube diameter positively affected both progeny sex ratio and body size. Sex ratio, but not progeny body mass, was negatively affected by short tube length. Building costs rose with increasing diameter accompanied by deteriorated efficiency of tube space utilization. Although female bees used a wide spectrum of nest dimensions, artificial nest tubes of 8-10 $\mathrm{mm}$ internal diameter and a length of at least $150 \mathrm{~mm}$ were optimal.
\end{abstract}

sex ratio / body size / nest cavity dimensions / diameter / length / Osmia bicornis=O. rufa

\section{INTRODUCTION}

Many cavity-nesting solitary bees use existing natural cavities such as hollow plant stems, beetle borer tunnels in dead wood, or empty snail shells to construct their nests within (Michener 2007). In contrast to ground nesting bees or species that build their nests on the surface of hard materials, females of xylophilous species depend on the dimensions of the prebuilt cavities that limit the space for brood cell construction. The internal diameter of the tube may limit brood cell volume and, thereby, progeny body size. Females can compensate for different nest diameters only par-

Electronic supplementary material The online version of this article (doi:10.1007/s13592-015-0380-z) contains supplementary material, which is available to authorized users.

Corresponding author: K. Seidelmann, karsten.seidelmann@zoologie.uni-halle.de Manuscript Editor: Peter Rosenkranz tially by adapting the length of the brood cell. Both the diameter and the length of the brood cell have to be large enough to allow formation of the provision mass as well as movements of the larva while spinning its cocoon. Moreover, the inner diameter determines the true building costs of nest construction at least by the area that has to be sealed by nesting material, such as mortar or leaf cuttings, to partition brood cells.

Cavity nesting species depend on the size spectrum of suitable cavities to construct nests. Especially in species with a sexual dimorphism in body size, progeny sex ratio can be expected to be influenced by the diameter of the selected cavities. Narrow tunnels force females to construct brood cells of the smaller sex (Longair 1981). Male biased sex ratios in narrow tubes have been reported, e.g., in Megachile rotundata (Stephen and Osgood 1965; Gerber and Klostermeyer 1972; O'Neill et al. 2010), Osmia lignaria (Torchio and Tepedino 1980; Tepedino and Torchio 1989), and Osmia bicornis (Raw 1972; Holm 
1973; Brechtel 1986). Also, progeny body size might be influenced (M. rotundata: O’Neill et al. 2010). Nest length might influence progeny sex ratio if brood cells for the sexes are restricted to particular regions of the linear nest. Short nest cavities should shift the sex ratio toward the sex whose brood cells are located at the entrance of the nest. Thus, the size spectrum of available nest cavities might have an impact on local population structure and stability (Ulbrich and Seidelmann 2001; Roulston and Goodell 2011).

In contrast to natural conditions, the dimensions of artificial nesting cavities can be governed in solitary bee-keepings to control progeny sex ratio and body size. For pollination purposes, it is advisable to maximize the number of females in the progeny and to produce large individuals that have a higher fecundity (e.g., Tepedino and Torchio 1989; Kim 1997; Tomkins et al. 2001; Bosch and Vicens 2006), lower winter mortalities (Tepedino and Torchio 1982; Bosch and Kemp 2004), and can be expected to work at cooler temperatures (Stone and Willmer 1989; Stone 1994). On the other hand, building costs of nest structures such as brood cell lining and partitions have to be minimized. Collection of construction materials consumes activity time that is diverted from time that could be used for provisioning and pollination. Last but not least, the offered cavity space should be sufficiently used by the bees.

The impact of nest tube dimension on reproduction parameters were studied in the red mason bee Osmia bicornis (L., syn.: O. rufa), a species that is regularly used as an orchard pollinator. Females of this protandric species construct mixed nests containing both sexes. Typically, nests consist of a series of cells for the later emerging sex (daughters) at the back of the tunnel and a series of the earlier emerging sex (sons) at the entrance (Raw 1972; Holm 1973; Maddocks and Paulus 1987). We analyzed nests of predefined dimensions from three consecutive nesting seasons. Several reproduction parameters were studied: progeny sex ratio, number of provisioned brood cells, and progeny body size as well as mortality and economical parameters (e.g., space usage, building efforts, and room efficiency). The aim of our study was first to identify optimal nest tube dimensions for the propagation of $O$. bicornis for pollination purposes and second to demonstrate the impact of tube dimensions on reproduction parameters in trap nests studies.

\section{MATERIAL AND METHODS}

Nest material and study designNest diameter range is limited by the body size of $O$. bicornis to $4 \mathrm{~mm}$ at the lower end and, due to the focus on a precise linear nest architecture for this study, to $12 \mathrm{~mm}$ at the upper end. At inner diameters above $12 \mathrm{~mm}$, O. bicornis females will construct longitudinal walls (Jacob-Remacle 1976; personal observations), thus constructing two cells in parallel. This leads to distorted construction costs that cannot be compared to smaller diameter nests. Artificial nest tubes were made from hollow stems of Japanese knotweed (Fallopia japonica, Houttuyn). The stems were cut into segments close to raised nodes to produce naturally sealed tubes. Internodes of $4,6,8,10$, and $12 \mathrm{~mm}$ inner diameter $(\varnothing)$ were selected by solid diameter gauges and trimmed afterwards to one of the five length classes: 70, 100, 130, 160, and $190 \mathrm{~mm}$ (distance between node diaphragm and opening). Five tubes of the same diameter class, one per length class, were combined into one round stalk bundle with all openings in one plane. The position of the length classes in each bundle was random. Ten bundles per diameter were prepared (containing 250 nest tubes in total). These 50 bundles were piled randomly into a cardboard box open to the front so that the tube openings of all bundles were in the same level. The box was then stuffed with styrofoam packing flakes from behind to stabilize the assembly.

Similarly constructed test boxes were offered to nesting females in three consecutive years in a regularly maintained population of $O$. bicornis located in the Botanical Garden of Halle/Saale (Germany, Saxony-Anhalt, $51^{\circ} 29^{\prime} 04 \mathrm{~N}, 11^{\circ} 56^{\prime} 07 \mathrm{E}$ ). This location provides a high diversity and stable richness of food plants. Effects of resource shortage or extensive traveling costs on maternal investment can be excluded (Kim 1999; Ulbrich and Seidelmann 2001; Ivanov 2006; Peterson and Roitberg 2006).

Beside the test block, additional nesting tubes of Japanese knotweed (various dimensions) and wooden nest blocks (tube dimensions $8 \times 150 \mathrm{~mm}, 100-120$ tubes per block) were offered in one and the same shelter that protected the nest material from rain and direct sunshine. Overwintered cocoons free of parasites were 
exposed in the first days of April in the shelter to allow natural emergence. Each year, a total of 800 nest tubes were offered to about 1000 emerging females to correct for a dispersal rate of about $40 \%$ (Seidelmann 2006). After the start of the nesting season, the test box was photographed every 2-3 days to monitor the sealing of the nest tubes. Temperature and humidity were registered by climate loggers (StowAway series; Onset Instruments) every 5 min over the whole nesting period. Mean temperature and relative humidity were calculated for the potential activity period of the bees (700 to $2100 \mathrm{~h}$; see Table S1 for a characterization of weather conditions). In July, all nests were removed from the Botanical Garden and stored in an empty honey bee hive at outdoor temperatures in the courtyard of the institute.

Nest analysisIn January, each nest was individually dissected by slitting the stalk with a scalpel on two sides to raise the upper half of the tube. Cocoons were removed and cleaned from feces and debris by hand. For each nest, the length of the vestibulum (empty cell at the entrance of the tube), size and content of every cell, as well as position and size of unused tube areas were recorded. Additionally, the weight of three entire cell partitions was noted. The length of cells was measured by an electronic sliding caliper (Preisser DIGI-MET 150 , precision $0.03 \mathrm{~mm}$ ) correct to $1 \mathrm{~mm}$, and the weight of cleaned cocoons and partitions by an electronic balance (Mettler Toledo ML104/01, precision $0.0001 \mathrm{~g}$ ) correct to $0.1 \mathrm{mg}$. To identify the sex of a bee and to check for parasites, cocoons were opened gently at the top. Bees were sexed according to the hair color of the clypeus (males: white; females: black). The sex of bee larvae that were killed by a parasite or perished by unknown reasons was inferred from the cell length and the sex of the bees in the neighboring cells (Raw 1972; Holm 1973; Longair 1981; Maddocks and Paulus 1987; Seidelmann 2006). As not all stalks were used for nest construction by $O$. bicornis, a total of 702 nests containing 5404 cells were analyzed from three nesting periods (2010-2012).

CalculationsSex ratio (proportion of daughters), parasitism rate, and mortality rate were calculated for each nest. Parasitism rate and mortality rate were defined as the number of cells parasitized or with dead siblings, respectively, per total number of provisioned cells of the nest. Usage of tube length was calculated as sum of the lengths of all provisioned cells per nest divided by the nominal tube length. Room efficiency was calculated per cell as quotient of cocoon mass per cell volume (calculated as cylinder volume from tube diameter and cell length). The estimation of diameter-specific construction costs was based on cell partition mass. The mass of building material per area was indicated as partition index. As the edges of the partitions are thicker than the diaphragm itself, the mass of a partition is a nonlinear function of the diameter:

$m_{\mathrm{p}}=A \times \pi d+B \times \frac{\pi}{4} d^{2}$

with $m_{\mathrm{p}}(\mathrm{mg})$ being the mass of the partition and $d(\mathrm{~mm})$ being the internal diameter of the nest tube. $A(\mathrm{mg} / \mathrm{mm})$ and $B\left(\mathrm{mg} / \mathrm{mm}^{2}\right)$ are factors that correct for different mortar expenditure to construct the diaphragm and the thickened edge, respectively. The factors were estimated by SPSS (IBM, ver. 22.0) and are given as estimated value \pm SE.

Statistical analysisNesting females adapt the progeny sex ratio and progeny body size to their age-specific provisioning capability (Torchio and Tepedino 1980; Ivanov 2006; Seidelmann 2006). To take these shifts into statistical account, the relative season date for each nest was determined as mean of start and closure dates (see electronic supplementary material for details) and normalized to a total nesting period of 50 days. The normalized date of tube occupation (= start date of construction of the first brood cell) was furthermore used to estimate the attractivity of tubes based on the assumption that bees occupy tubes of preferred dimensions first.

The impact of nest tube dimensions was analyzed by GLM univariate ANOVA in SPSS (IBM, ver. 22.0) with diameter and length as fixed factors, year as random factor, and season date as covariate. Parameters such as progeny sex ratio, cell number, and rate of parasitism were analyzed per nest, while parameters of individual offspring such as cocoon mass, cell volume, and derived values were analyzed on the basis of provisioned brood cells. Due to the sexual size dimorphism in body size, sex was used as additional fixed factor in these analyses. Moreover, to correct for sexual dimorphism effects in the analysis of room efficiency, cocoon mass had to be 
used as an additional covariate. Differences between nest dimensions were tested as contrasts against the largest dimension value. Females were assumed to suffer no spatial limitations in nests of the largest dimensions and to be able to provision cells in a manner optimal for their fitness. Values in the text and figures are given as mean \pm standard deviation unless otherwise stated. The error level was set to $\alpha=0.05$.

\section{RESULTS}

\subsection{General usage of nest tubes}

Osmia bicornis females accepted tubes of all supplied dimensions. However, bees used only $57.2 \%$ of the $4-\mathrm{mm}$ tubes, while $100 \%$ of the 6-12-mm tubes were occupied. Tube attractivity as assessed by the date of occupation did not depend on tube dimensions in general (diameter $-F_{4,658}=1.98, p=0.190$; length $-F_{4}$, $658=2.44, p=0.129$ ). However, narrow tubes $(4 \mathrm{~mm})$ were occupied later than thicker ones (Figure 1; all Scheffé post hoc test- $\mid$ diff $\mid \geq 9.920$, $\mathrm{SE} \geq 1.352, p<0.001)$. Tubes of $\varnothing \geq 6 \mathrm{~mm}$ did not differ in the mean occupation date (all

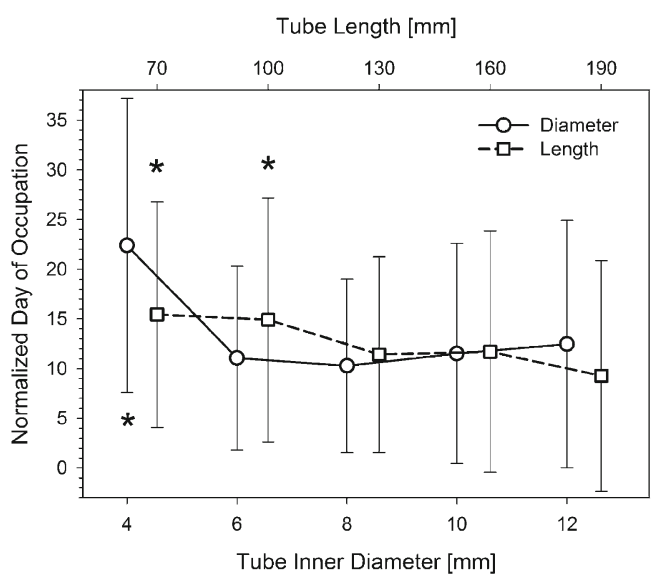

Figure 1. Occupation date of nest tubes by $O$. bicornis females according to tube diameter (circles, solid line, bottom axis, sum of all length classes) and tube length (squares, dashed line, top axis, sum of all diameter classes). Symbols refer to mean $\pm \mathrm{SD}$; asterisks mark significant differences from the largest diameter or length class, respectively. $\mid$ diff $\mid \leq 2.174, \mathrm{SE} \leq 1.365, p \geq 0.459)$. Shorter tubes were less attractive to the bees compared with the longest ones (Figure 1; all $|\operatorname{diff}| \geq 5.635$, $\mathrm{SE} \geq 1.266, p<0.001)$. The three longer tube classes did not differ in occupation date (all | diff $\mid \leq 2.446, \mathrm{SE} \leq 1.290, p \geq 0.431$ ).

\subsection{Progeny body size and sex ratio}

Mean cocoon mass differed between the sexes (sons-85.31 $27.52 \mathrm{mg}, n=1481$; daughters- $150.02 \pm 30.62 \mathrm{mg}, n=3127 ; F_{1}$, $4608=114.5, p=0.002)$ and was influenced by nest tube diameter $\left(F_{4,4608}=101.8, p<0.001\right)$, but not by tube length (Figure 2c; $F_{4}, 4608=0.49$, $p=0.742$ ). The cocoon mass of daughters increased with the diameter up to $10 \mathrm{~mm}$ (all $\mid$ diff $\mid \geq 0.008, \mathrm{SE} \geq 0.001, p<0.001)$ and was not further increased in wider tubes (diff $=0.002$, $\mathrm{SE}=0.001, p=0.088$ ). In sons, only cocoons from the two narrowest diameter classes were lighter than the ones from the widest tubes (Figure 2c; both $\mid$ diff $\mid \geq 0.016, \mathrm{SE}=0.002, p<0.001$; all $\varnothing$ $>6 \mathrm{~mm},|\operatorname{diff}| \leq 0.002, \mathrm{SE}=0.002, p \geq 0.311)$. Cocoon mass did not differ between years $\left(F_{2}\right.$, $4608=7.26, p=0.087$ ).

The overall sex ratio (proportion of daughters) for all cells including those that were parasitized ranged between $0.608 \pm 0.313$ in 2010 and 0.538 \pm 0.292 in 2012. Sex ratio depended on diameter $\left(F_{4,658}=257.8, p<0.001\right)$ but not on nest length $\left(F_{4}, 658=3.20, p=0.074\right)$. In $\varnothing=4 \mathrm{~mm}$ nests, daughter cells were constructed by way of exception only. The proportion of daughters increased with the diameter up to $8 \mathrm{~mm}$ (all $\mid$ diff $\mid \geq 0.742$, $\mathrm{SE} \geq 0.024, p<0.001$ ) but was not further increased in wider tubes (Figure 2b; all $|\operatorname{diff}| \leq 0.008$, $\mathrm{SE} \leq 0.024, p \geq 0.746$ ). Although sex ratio did not depend on nest tube length in general, nests of $70 \mathrm{~mm}$ produced a higher proportion of sons than the longest nests $(\operatorname{diff}=-0.114, \mathrm{SE}=0.027$, $p<0.001)$ while all other length classes did not differ ( $\mid$ diff $\mid \leq 0.049, \mathrm{SE} \leq 0.26, p \geq 0.059$ ). The missing general impact of tube length was an unexpected effect of entering "year" as a random factor in the model. Analyzing the years individually, sex ratio increased with length in each individual year (Figure S1; $2010-F_{2,212}=5.84, p<0.001$; $2011-F_{2,244}=5.40, p<0.001 ; 2012-F_{2}$, 
Tube Length [mm]
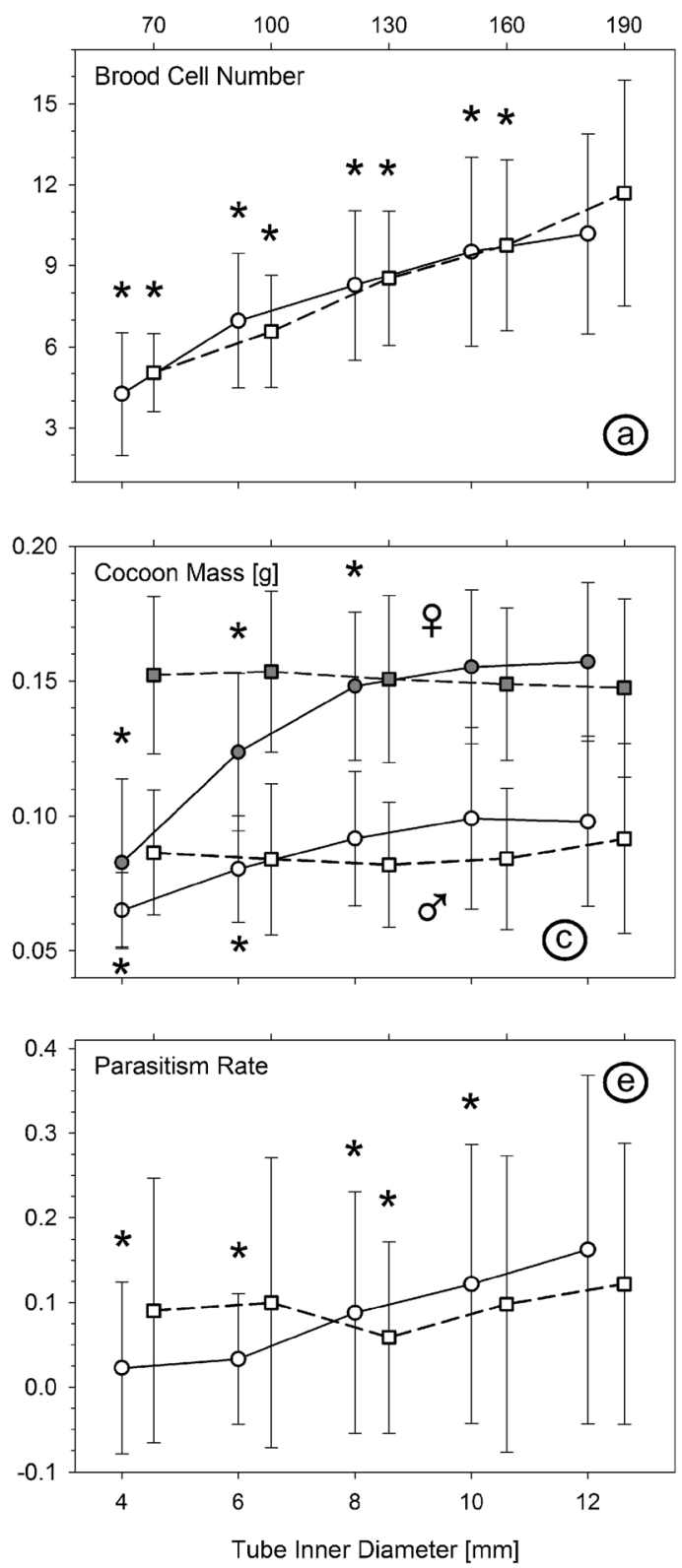

Tube Length [mm]
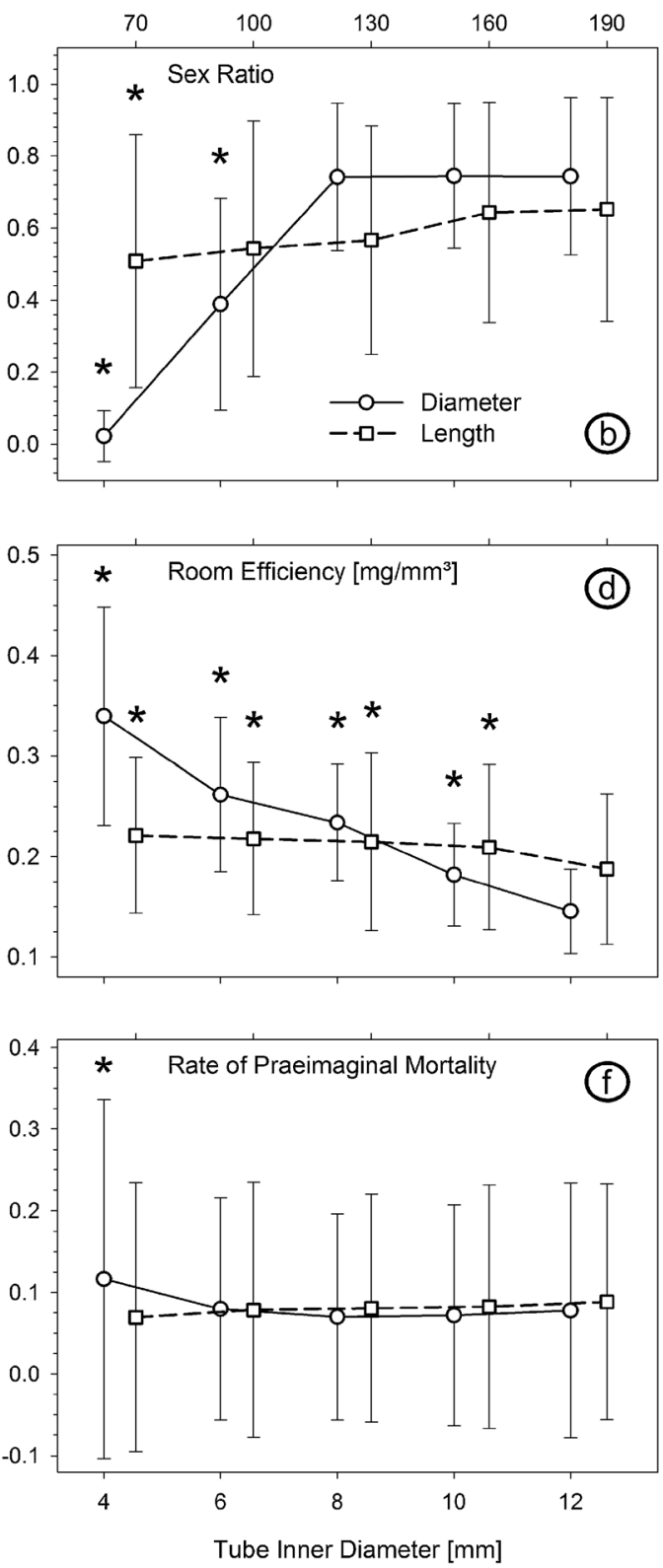

Figure 2. Parameters of nests constructed by $O$. bicornis depending on tube inner diameter (circles, solid line, bottom axis, sum of all length classes) and tube length (squares, dashed line, top axis, sum of all diameter classes). a Number of cells constructed per nest. b Progeny sex ratio (proportion of daughters) per nest. c Cocoon mass as indicator for body size (open symbols refer to sons and gray ones to daughters). d Room efficiency. e Rate of parasitism. $\mathbf{f}$ Rate of preimaginal mortality due to unknown reasons. Symbols refer to mean $\pm \mathrm{SD}$, asterisks identify significant differences to the largest diameter or length class, respectively.

$202=3.07, p=0.018$ ). The outliers found in 2010 and 2011 mask the trend of increasing sex ratios with lengthened tubes in the general analysis (see electronic supplementary material for details). 


\subsection{Brood cell number, space usage, and construction effort}

The number of brood cells constructed per nest depended on both nest dimensions (Figure 2a; diameter $-F_{4,658}=13.34, p=0.001$; length $-F_{4}$, $\left.{ }_{658}=145.8, p<0.001\right)$ and ranged between $2.7 \pm 1.1$ cells in $4 \times 70 \mathrm{~mm}^{2}$ nests and $13.8 \pm 3.9$ cells in $12 \times 190 \mathrm{~mm}^{2}$ tubes. However, the longer tubes were used for a higher number of brood cells in the larger diameter classes only $(160 \mathrm{~mm}$ nests in $\varnothing \geq 6 \mathrm{~mm}, 190 \mathrm{~mm}$ nests in $\varnothing \geq 8 \mathrm{~mm}$; $\left.L \times D-F_{16,658}=2.85, p=0.007\right)$.

In total, $73.3 \pm 16.7 \%(n=651)$ of the available nest tube length was used to construct brood cells, a vestibulum, and a nest plug. The total length used did not depend on nest tube diameter $\left(F_{4}\right.$, $\left.{ }_{651}=0.57, p=0.691\right)$ or length $\left(F_{4,651}=2.72\right.$, $p=0.101)$. However, there was an interaction between diameter and length $\left(F_{16,651}=2.09\right.$, $p=0.039)$ caused by differences between length classes at $\varnothing \leq 6 \mathrm{~mm}$ (all $F_{4,73 / 147} \geq 2.85$, all $p \leq 0.030$ ). Room efficiency (cocoon mass per brood cell volume, Figure $2 \mathrm{~d}$ ) depended on tube diameter $\left(F_{4,4575}=55.99, p<0.001\right)$, length $\left(F_{4}\right.$, $4575=7.52, p=0.006)$, progeny body size $\left(F_{1}\right.$, $4575=2132, p<0.001)$, but not on sizedimorphism-adjusted sex $\left(F_{1,4575}=0.14\right.$, $p=0.734$ ).

The mean mass of partitions increased with diameter (Figure 3, $F_{4,1125}=396.5, p<0.001$ ), but did not depend on nest length $\left(F_{4,1125}=0.66\right.$, $p=0.630)$. The partition index decreased with diameter (Figure 3, $F_{4,1125}=7.76, p=0.006$ ) and was also independent from nest tube length $\left(F_{4}\right.$, $1125=1.60, p=0.242$ ). However, the mass of the partitions corresponds well to the value expected under a fixed solidity of the edges and diaphragm. The constants of the nonlinear regression (Eq. 1) were estimated to $A=2.22 \pm 0.41 \mathrm{mg} / \mathrm{mm}$ as mortar expenditure for the edge and $B=1.30 \pm 0.16 \mathrm{mg} /$ $\mathrm{mm}^{2}$ for the diaphragm $\left(R^{2}=0.359\right)$.

\subsection{Mortality and parasitism}

Brood cells were parasitized by Cacoxenus indagator (Diptera: Drosophilidae, $6.1 \%$ ), Chaetodactylus osmiae (Acari: Chaetodactylidae, $1.1 \%)$, Monodontomerus obscurus
(Hymenoptera: Torymidae, $1.1 \%$ ), and Anthrax anthrax (Diptera: Bombyliidae, $<0.1 \%$ ), or destroyed by Aphomia sociella (Lepidoptera: Pyralidae, $1.0 \%$ ). Rate of infestation by parasites and nest destroyers increased with tube diameter (Figure 2e; $F_{4,658}=7.09, p=0.009$, see electronic supplementary material for details), but was independent from tube length $\left(F_{4}, 658=1.68\right.$, $p=0.240)$. Parasitism by the different species varied from year to year $\left(\chi^{2}=448.8, d f=10\right.$, $p<0.001)$. In $51.9 \%$ of the cells infested by C. indagator and Ch. osmiae, bee larvae survived in spite of the parasitization.

Beside losses from parasitism, $8.0 \%$ of the eggs, larvae, or pupae died without detectable reason. This preimaginal mortality varied between years $\left(F_{2,658}=48.22, p=0.001\right)$ and was influenced solely by the tube diameter (Figure $2 \mathrm{f} ; F_{4}$, $\left.{ }_{658}=4.18, p=0.038\right)$, but not by tube length $\left(F_{4}\right.$, $\left.{ }_{658}=0.65, p=0.644\right)$. Both factors, mortality due to parasitism and due to unknown reasons, altered the sex ratio from $0.580 \pm 0.332$ created by the mother bees to a ratio of $0.611 \pm 0.351$ of emerging offspring $(t=-6.63, d f=649, p<0.001)$. Sons suffered from higher parasitism $(13.0 \%)$ than daughters $\left(8.4 \%, \chi^{2}=22.30, d f=1, p<0.001\right)$. Moreover, mortality due to unknown reasons was also higher in sons $(11.3 \%)$ than in daughters $(6.2 \%$, $\left.\chi^{2}=42.32, d f=1, p<0.001\right)$.

\section{DISCUSSION}

Solitary bees nesting in pre-existing cavities rely on the supply of appropriate hollows for reproduction. Suitable tube-like cavities in wood or plant stems are limited resources (Roulston and Goodell 2011). Females are forced by the unpredictability of the dimensions of available nest tubes and the limitations by small diameters on the body size of progeny to use any discovered tubes as economically as possible. Especially for a species with a distinctive sex dimorphism in body size, females should adapt the sex ratio of progeny in the nest under construction. If the actual tube does not limit progeny body size, females can be expected to shift their actual investment toward the upper boundary of the projected conditional progeny body size spectrum (Seidelmann et al. 2010). This body size optimization implies also 


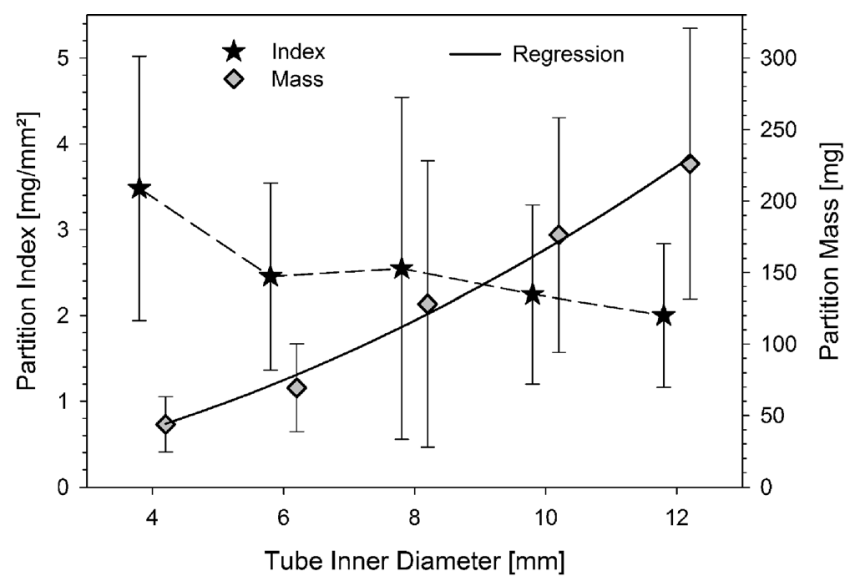

Figure 3. Partition index and mass of $O$. bicornis cell partitions according to nest tube inner diameter. Stars with dashed line: partition index; diamonds : partition mass; solid line: nonlinear regression of partition mass. Symbols refer to mean \pm SD.

an adjustment of progeny sex ratio in favor of the larger sex. Providing solely nest tubes of large dimensions maintains this shift, but is not able to drive mean body size over the species-specific optimum and Fisherian sex ratio (Tepedino et al. 1984; Seidelmann et al. 2010, 2014). The observed female biased progeny sex ratio and deviations from typical mean body size in our study result from the restricted number of nest tubes leading to an overrepresentation of nests constructed early in the nesting season. Young bees construct more daughter cells and progeny of larger body size (Torchio and Tepedino 1980; Tepedino and Torchio 1982; Tomkins et al. 2001; Seidelmann 2006; this study-Table S2).

A presupposition for the rearing of any solitary bee is the acceptance of the offered nest materials. Osmia bicornis females did not prefer a particular internal tube diameter in our study. The lower acceptance of $4 \mathrm{~mm}$ tubes could be a body size exclusion phenomenon. In contrast to the low diameter discrimination in our study, O. bicornis females preferred in other studies either narrow nest diameters of 5-6 $\mathrm{mm}$ (Free and Williams 1970; Tasei 1973; Brechtel 1986) or wider nests of 7-9 mm (Jacob-Remacle 1976; Maddocks and Paulus 1987; Ivanov 2006). This inhomogeneity of preferred diameters reflects the diversity of bee body size found in autochthony and managed populations. In contrast to the diameter, preferences for certain nest tube length likely were not due to nesting female body size. Although all length classes were used by the bees in our study, the shorter ones (70 and $100 \mathrm{~mm}$ ) were occupied later than the longer ones, indicating a preference for deeper nest tubes. This result is consistent with increasing frequencies of occupation of reed tubes up to $230 \mathrm{~mm}$ depth (Ivanov 2006), but only partly consistent with the preference of $120-\mathrm{mm}$ tubes over both 140- and 100-mm tubes (Maddocks and Paulus 1987).

Both nest tube dimensions were found to influence the reproduction parameters of $O$. bicornis females. The diameter had generally a deeper impact than the tube length. Sex ratio and body mass increased from the smallest diameter towards 8- and 10-mm tubes, respectively, and remained nearly constant afterwards. On the contrary, parameters of economical space usage (e.g., room efficiency) decreased with increasing diameter. Also, the effort to construct cell partitions increased with tube width, although females adhered to their construction principle and did not thicken the structure to support stability. Offspring quality and economy of nest construction form an optimum of productivity at internal nest tube diameters of 8-10 $\mathrm{mm}$.

The expected male biased sex ratio in short nest tubes was restricted to nests of $70 \mathrm{~mm}$ length. A general trend of increasing proportions of daughters with increasing nest tube length (Gruber et al. 2011) was not consistently found in our study. 
However, the impact of tube length can be expected to diminish above a critical number of brood cells. Females construct a few brood cells for sons at the entrance of the nest (e.g., Raw 1972; Maddocks and Paulus 1987; Ivanov 2006). Therefore, short tubes limit the space left over for the construction of brood cells for daughters. Above a critical length, however, the space is sufficient to realize the sex ratio projected by mother bee's condition, and sex ratio should be unaffected by the nest tube length. Finally, the risk spreading principle (Torchio and Tepedino 1980) should restrict the number of cells produced in a single nest. The resulting decrease of space usage, however, was not found at least in the length range studied by us.

\section{CONCLUSION}

Osmia bicornis females accept nest tubes of a wide range of diameters and length. Tubes of $\geq 6 \mathrm{~mm}$ diameter and $\geq 100 \mathrm{~mm}$ length are sufficiently accepted for a commercial propagation. The proportion of daughters and progeny body size reached their maximum at $8-10 \mathrm{~mm}$ inner tube diameter. Wider tubes are not recommended because parasitism and building costs increase with diameter. The optimal length of nest tubes for the propagation of $O$. bicornis has to be oriented on the sex ratio shift toward males in tubes shorter than $130 \mathrm{~mm}$, and on practical demands as handling and procurement of nest tubes. Tubes in the range of $8-10 \mathrm{~mm}$ diameter and 150 to $200 \mathrm{~mm}$ length were found to be optimal. These recommendations apply also for trap nest studies to avoid a male biased sex ratio and a distorted body size spectrum. Nests constructed early in the nesting season are especially valuable for pollination purposes as they contain the highest proportion of daughters and bees of the largest body size.

\section{ACKNOWLEDGMENTS}

We are grateful to Annica Schneider for collecting the data of the year 2011. We thank two anonymous reviewers for their helpful comments. The study was supported by the institute of Biology/Zoology, M.-Luther-University Halle (Saale), Germany.
L'impact des dimensions du tube de nidification sur les paramètres de la reproduction chez Osmia bicornis (Hymenoptera: Megachilidae), une abeille solitaire nichant dans une cavité

sex ratio / taille du corps / dimensions du nid / diamètre / longueur

Der Einfluss der Größe der Niströhren auf die Reproduktionsparameter bei einer in Hohlräumen nistenden Solitärbiene, Osmia bicornis (Hymenoptera: Megachilidae)

\section{Geschlechterverhältnis / Körpergröße / Niströhrengröße / Durchmesser / Länge}

\section{REFERENCES}

Bosch, J., Kemp, W.P. (2004) Effect of pre-wintering and wintering temperature regimes on weight loss, survival, and emergence time in the mason bee Osmia cornuta (Hymenoptera: Megachilidae). Apidologie 359 (5), 469-479

Bosch, J., Vicens, N. (2006) Relationship between body size, provisioning rate, longevity and reproductive success in females of the solitary bee Osmia cornuta. Behav. Ecol. Sociobiol. 60(1), 26-33

Brechtel, F. (1986) Die Stechimmenfauna des Bienenwaldes und seiner Randbereiche (Südpfalz) unter besonderer Berücksichtigung der Ökologie kunstnestbewohnender Arten. - Pollichia-Buch Nr. 9, Bad Dürkheim

Free, J.B., Williams, I.H. (1970) Preliminary investigations on the occupation of artificial nests by Osmia rufa L. (Hymenoptera: Megachilidae). J. Appl. Ecol. 7 (3), 559-566

Gerber, S., Klostermeyer, E.C. (1972) Factors affecting the sex ratio and nesting behavior of the alfalfa leafcutter bee. Wash. Agric. Exp. Statn. Techn. Bull. 73, 1-11

Gruber, B., Eckel, K., Everaars, J., Dormann, C.F. (2011) On managing the red mason bee (Osmia bicornis) in apple orchards. Apidologie 42 (5), 564-576

Holm, S.N. (1973) Osmia rufa L. (Hym. Megachilidae) as a pollinator of plants in greenhouses. Entomol. Scand. 4, 217-224

Ivanov, S.P. (2006) The nesting of Osmia rufa (L.) (Hymenoptera, Megachilidae) in the Crimea: structure and composition of nests. Entomol. Rev. 86(5), 524-533

Jacob-Remacle, A. (1976) Une operation nichoirs artificiels pour Hymenopteres dans trois jardins de Liege. Bull. Ann. Soc. R. Entomol. Belg. 112 (10-12), 219-242

Kim, J.-Y. (1997) Female size and fitness in the leaf-cutter bee Megachile apicalis . Ecol. Entomol. 22 (3), 275282 
Kim, J.-Y. (1999) Influence of resource level on maternal investment in a leaf-cutter bee (Hymenoptera: Megachilidae). Behav. Ecol. 10 (5), 552-556

Longair, R.W. (1981) Sex ratio variations in xylophilous aculeate Hymenoptera. Evolution 35 (3), 597-600

Maddocks, R., Paulus, H.F. (1987) Quantitative Aspekte der Brutbiologie von Osmia rufa L. und Osmia cornuta Latr. (Hymenoptera, Megachilidae): Eine vergleichende Untersuchung zu Mechanismen der Konkurrenzminderung zweier nahverwandter Bienenarten. Zool. Jahrb. Abt. Syst. Ökol. Geogr. Tiere $114(1), 15-44$

Michener, C.D. (2007) The bees of the world, 2nd edn. Johns Hopkins University Press, Baltimore

O'Neill, K.M., Pearce, A.M., O'Neill, R.P., Miller, R.S. (2010) Offspring size and sex ratio variation in a feral population of alfalfa leafcutting bees (Hymenoptera: Megachilidae). Ann. Entomol. Soc. Am. 103 (5), 775-784

Peterson, J.H., Roitberg, B.D. (2006) Impacts of flight distance on sex ratio and resource allocation to offspring in the leafcutter bee, Megachile rotundata. Behav. Ecol. Sociobiol. 59(5), 589-596

Raw, A. (1972) The biology of the solitary bee Osmia rufa (L.) (Megachilidae). Trans. R. Entomol. Soc. Lond. 124 (3), 213-229

Roulston, T.H., Goodell, K. (2011) The role of resources and risks in regulating wild bee populations. Ann. Rev. Entomol. 56(1), 293-312

Seidelmann, K. (2006) Open-cell parasitism shapes maternal investment patterns in the Red Mason bee Osmia rufa. Behav. Ecol. 17(5), 839-848

Seidelmann, K. (2014) Optimal progeny body size in a solitary bee, Osmia bicornis (Apoidea: Megachilidae). Ecol. Entomol. 39(5), 656-663

Seidelmann, K., Ulbrich, K., Mielenz, N. (2010) Conditional sex allocation in the Red Mason bee, Osmia rufa. Behav. Ecol. Sociobiol. 64 (3), 337-347
Stephen, W.P., Osgood, C.E. (1965) Influence of tunnel size and nesting medium on sex-ratios in a leafcutter bee, Megachile rotundata. J. Econ. Entomol. 58(5), 965-986

Stone, G.N. (1994) Activity patterns of females of the solitary bee Anthophora plumipes in relation to temperature, nectar supplies and body size. Ecol. Entomol. 19 (2), 177-189

Stone, G.N., Willmer, P.G. (1989) Warm-up rates and body temperatures in bees: the importance of body size, thermal regime and phylogeny. J. Exp. Biol. 147, 303-328

Tasei, J.N. (1973) Le comportement de nidification chez Osmia (Osmia) cornuta Latr. et Osmia (Osmia) rufa (L.) (Hym. Megachilidae). Apidologie 4 (3), 195-225

Tepedino, V.J., Torchio, P.F. (1982) Phenotypic variability in nesting success among Osmia lignaria propinqua females in a glasshouse environment (Hymenoptera: Megachilidae). Ecol. Entomol. 7 (4), 453-462

Tepedino, V.J., Torchio, P.F. (1989) Influence of nest hole selection on sex ratio and progeny size in Osmia lignaria propinqua (Hymenoptera: Megachilidae). Ann. Entomol. Soc. Am. 82 (3), 355-360

Tepedino, V.J., Thompson, R., Torchio, P.F. (1984) Heritability for size in the megachilid bee Osmia lignaria propinqua Cresson. Apidologie 15(1), 83-87

Tomkins, J.L., Simmons, L.W., Alcock, J. (2001) Broodprovisioning strategies in Dawson's burrowing bee, Amegilla dawsoni (Hymenoptera: Anthophorini). Behav. Ecol. Sociobiol. 50(1), 81-89

Torchio, P.F., Tepedino, V.J. (1980) Sex ratio, body size and seasonality in a solitary bee, Osmia lignaria propinqua Cresson, (Hymenoptera: Megachilidae). Evolution 34 (5), 993-1003

Ulbrich, K., Seidelmann, K. (2001) Modelling population dynamics of solitary bees in relation to habitat quality. Web Ecol. 2 (1), 57-64 